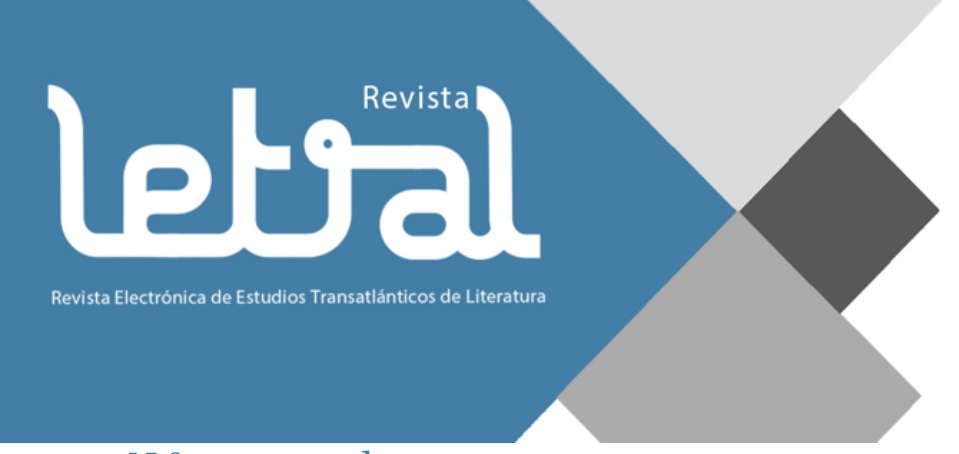

N. ${ }^{\circ} 25$, enero de 2021

\title{
Los poemas del pie-boca. Retórica de la discapacidad en la poesía de Gabriela Brimmer
}

\author{
The Poems of the Foot-Mouth. Political Rhetoric \\ of Disability in Gabriela Brimmer's Poetry
}

Carlos Ayram

Pontificia Universidad Católica de Chile/ANID, cjayram@uc.cl

ORCID: 0000-0002-6043-0884

\section{Date of reception: \\ $26 / 10 / 2020$ \\ Date of acceptance: \\ 13/01/2021}

Citation: Ayram, Carlos. "Los poemas del pie-boca. Retórica de la discapacidad en la poesía de Gabriela Brimmer". Revista Letral, n. ${ }^{\circ}$ 25, 2021, pp. 24-53.

ISSN 1989-3302.

DOI:

http://doi.org/10.30827/RL.voi 25.16303

Funding data: El presente artículo es parte del proyecto de tesis doctoral: "Espectros de la discapacidad. Retóricas y representaciones del cuerpo tullido en la narrativa conosureña y mexicana reciente". El proyecto está financiado por la Agencia Nacional de Investigación y Desarrollo de Chile (ANID) y la Pontificia Universidad Católica de Chile y está guiado por la Dra. Macarena Areco, profesora asociada de Facultad de Letras de la misma universidad.

License: This content is under a Creative Commons AttributionNonCommercial, 3.0 Unported license.

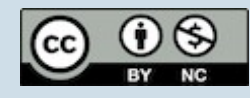

\section{RESUMEN}

El presente artículo problematiza la construcción de una retórica política de la discapacidad en la producción poética elaborada por la activista y escritora mexicana Gabriela Brimmer (1947-2000). Argumento que Brimmer con su proyecto poético desafía las condiciones de producción convencionales de la poesía, acudiendo a formas alternativas de visibilidad autorial y material, que le proporcionan construir un espacio de disidencia corporal investida políticamente por la experiencia encarnada de la parálisis cerebral. De esta manera, Gabriela construye una serie de imágenes que se convierten en un registro testimonial y singular en relación con su experiencia como mujer, escritora y activista. Sostengo que la poesía es un saber alternativo -ni patológico, ni diagnóstico- desde la discapacidad que logra deshacer las imágenes del sufrimiento, la tragedia y el padecimiento asociadas a un sujeto embargado por el discurso médico-rehabilitador.

Palabras clave: Gaby Brimmer; poesía; discapacidad; retórica.

\begin{abstract}
This article problematizes the construction of political rhetoric of disability in the poetic production of Mexican activist and writer Gabriela Brimmer (1947-2000). I argue that the exercise of poetization that Brimmer undertakes, which is part of her autobiographical project, challenges the conventional production conditions of poetry. She was resorting to alternative forms of authorial and material visibility, which provided her with the construction of a space of bodily dissidence invested politically by the incarnated cerebral palsy experience. In this way, Brimmer constructs a series of images that become a testimonial and singular record about her experience as a woman, writer, and activist. I maintain that poetry is an alternative knowledge - neither pathological nor diagnostic-from the perspective of disability that manages to undo the images of suffering, tragedy, and suffering associated with a subject seized by the medical-rehabilitative discourse.
\end{abstract}

Keywords: Gaby Brimmer; poetry; disability; rhetoric. 
Me hice un tajo en el vientre Y con el dedo índice

Re pa so

Cesura

La herida es nuestra

Evidencia

Daniela Catrileo, Río herido

\section{Introducción}

En 1979, Gabriela Brimmer publicó su autobiografía, Gaby Brimmer, en la editorial Grijalbo en coautoría con la escritora mexicana Elena Poniatowska Amor. La obra puede ser considerada un hito dentro de una genealogía de escrituras del yo sobre la discapacidad en América Latina, y según Beth E. Jörgensen, se anticipó al desarrollo de los movimientos sociales de las personas con discapacidad en la década del 70 en México: “Brimmer's life story was narrated, edited, and published in a virtual literary and cultural vacuum and in a context of extreme social exclusion of the disabled" (68). La historia de Gabriela -escrita por ella y editada por Poniatowska- podría ser considerada una primera forma de archivo sobre una memoria regional de la discapacidad, que se opuso tempranamente a las políticas discapacitantes, segregadoras y excluyentes que dominaron gran parte de la vida y existencia de sujetos considerados "minusválidos" por un sistema político, cultural, social y económico en América Latina.

Si durante la década del setenta en el contexto anglosajón, colectivos marxistas y sociopolíticos como Union of the Physically Impaired Against Segregation (UPIAS), en Inglaterra, e The Independent Living Movement, en los Estados Unidos, impugnaron las concepciones dominantes sobre la discapacidad como un problema médico, individual y trágico, en nuestra región, la participación política de Brimmer en el espacio público e institucional, sumada a su compromiso con la escritura, desfamiliarizó los guiones culturales asignados a una comunidad conceptuada e imaginada como paralítica, impedida o inválida. Un saber particular y sensible se desarrolló a través de su experiencia de descalificación y produjo, asimismo, un registro epistemológico y ontológico muy distinto que la sitúo como agente -en su acepción de agencia- encargada de la construcción de una subjetividad que no cupo más en espacios de dominación y control 
médico. La autobiografía en cuanto objeto verbal y producto de una experiencia corporal, se convirtió en un espacio de producción de sentidos políticos que se organizaron y cohesionaron en función de la aparición pública de un cuerpo femenino no normativo que encontró en la escritura una alternativa diferente, contestataria y radical sobre su posición en el mundo y en el campo cultural.

Gaby Brimmer narra la vida de Gabriela, desde su posición como testigo, junto con otras dos voces que participan de la reconstrucción de su historia en medio de instituciones de rehabilitación, geriátricos, universidades y centros de cuidado: Florencia, la nana/cuidadora, y Saris, su madre, una trinidad testimonial implicada en la construcción de una obra 'anfibia', que bien podría moverse entre los terrenos de la autobiografía, la crónica y el testimonio. Más que una historia ejemplar sobre los desafíos y obstáculos que supera inesperadamente un sujeto con parálisis cerebral y los múltiples accesos que tuvo que conquistar durante su vida -y como han constatado, por ejemplo, los comentarios de Efraín Huertas y Joaquín Sabines sobre el prodigio, milagro y tenacidad que vieron en Gaby- el espacio autobiográfico sirvió a su autora con un propósito intelectivo, simbólico y material: más allá de la milagrosa conquista de la escritura, Gabriela se autoconstruye como sujeto y, a su vez, escribe su cuerpo, interpretando sus necesidades y develando la potencia de una materialidad asumida como defectuosa. Por el factor RH de sus padres, Gabriela fue diagnosticada a los tres días de nacida con parálisis cerebral y gran parte de su vida fue asistida por su madre y su nana en labores cotidianas; sin embargo, durante su infancia, Gabriela descubrió que podía controlar su pie izquierdo y empezó a comunicarse, primero, en una tabla $\mathrm{ABC}$ y, más tarde, en una máquina de escribir: el registro escrito de su vida estuvo atado al movimiento del pie y fue este el que le dio forma a la constitución del material escrito': "Aparte de escribir a máquina, tejo y pinto con el pie izquierdo, es por eso que lo llamo mi pieboca" (Brimmer-Poniatowska 51).

Llama la atención que la construcción escrita de Gabriela no operó solo a nivel de una prosa implicada en su experiencia, primero como paciente, luego como activista: se ordenó también en el ejercicio de la poesía, donde ella inventó una serie de hablantes poéticos que sirvieron de manera complementaria al 
registro autobiográfico ${ }^{1}$. La poesía, no obstante, no debe ser entendida como suplemento al texto principal: en ella hay una redondez de la experiencia corporal y de la imaginación política que debe ser tenida en cuenta a la hora de comprender los propósitos comunicativos de estos objetos verbales.

Después de la publicación de la autobiografía, Gabriela publicó en 1980, nuevamente en Grijalbo, Gabriela. Un año después, una colección de 91 poemas, que según Elena Poniatowska "no conoció el éxito del libro anterior" (1). Ahora, ¿Cuál es el presunto éxito editorial que despertó la autobiografía, pero que el libro de poemas no tuvo? Una hipótesis provisional permitiría especular que la autobiografía tuvo mayor circulación como prosa y documento literario por la coautoría: un texto cuyo "modelo de doble cabeza” (190), al decir de Susan Antebi (2009), permitió que el libro tuviera una mayor difusión y, por tanto, logró encontrar a su comunidad de lectores. Sin embargo, dentro del texto autobiográfico, la poesía aparece como destello y signo de resistencia. La edición de 1979 incorporó muchos poemas escritos por el pie-boca de Gabriela que aparecen en medio de las distintas diégesis que conforman la obra. La poesía expande y complejiza la experiencia, aumenta e intensifica la capacidad de agencia de Gabriela y participa de la construcción de una imaginación diferente sobre la discapacidad, deshaciendo su dimensión medicalizada. Los textos no solo ejemplifican sentimientos o apelan retóricamente a un pathos que el texto precisa para lograr la efectividad de la trasmisión del mensaje, antes bien, los poemas se constituyen en el archivo de un cuerpo que modela estrategias retóricas de resistencia.

El presente artículo problematiza la construcción de una retórica política de la discapacidad en la producción poética elaborada por Gabriela Brimmer. Por ello, trabajaré con una selección de poemas provenientes tanto de la autobiografía como del libro Gabriela. Un año después. Sostengo que el ejercicio de poetización que emprende Brimmer desafía las condiciones de producción convencionales de la poesía, acudiendo a formas alternativas de visibilidad autorial y material, que le proporcionan construir un espacio de disidencia corporal investida

${ }^{1}$ Gabriela fue una asidua lectora de poesía y se inspiró en el trabajo de Rosario Castellanos por recomendación de su madre; de hecho, fue ella durante mucho tiempo su albacea y crítica más cercana. 
políticamente por la experiencia encarnada de la parálisis cerebral. De esta manera, Brimmer construye una serie de imágenes que se convierten en un registro testimonial y singular en relación con su experiencia como mujer, escritora y activista. La poesía se convierte es una suerte de saber alternativo -ni patológico, ni diagnóstico- sobre/desde la discapacidad que logra deshacer las imágenes del sufrimiento, la tragedia y el padecimiento asociadas a un sujeto embargado por el discurso médico-rehabilitador.

En consecuencia, el artículo se encuentra organizado en tres secciones. Primero, discuto la manera como Gabriela usa deliberadamente el ejercicio poético y autobiográfico en busca de una construcción retórica diferente de la discapacidad, cuya función repiensa los modos en que un cuerpo es capaz de auto-representarse lejos de los modelos discursivos inspirados en el imperativo de la medicalización de la vida. Segundo, se analiza un corpus de poemas agrupados en tres grupos temáticos: los afectos; el amor y la sexualidad; y la voz política. Finalmente, concluyo con algunas consideraciones para pensar el ejercicio de la poesía de Gabriela en su constitución como saber alternativo y radicalmente político desde la discapacidad.

\section{Una retórica de la discapacidad}

Históricamente la discapacidad ha sido conceptuada e imaginada en sociedades occidentales como una enfermedad y una tragedia individual que se puede curar, corregir o erradicar y en la que no cabe promesa alguna de futurización. De acuerdo con Alison Kafer (2013) "If Disability is conceptualized as a terrible unending tragedy, then any future that includes disability can only be a future to avoid" (2). La discapacidad fue entendida como una deficiencia biofísica o mental que padecían determinados sujetos que no cumplían con las exigencias de una sociedad normativa y, por tanto, fueron disminuidos ontológicamente como pacientes, marcados social y culturalmente como indeseables. Esta definición se integró a lo que Len Barton, Colin Barnes, Mike Oliver, Tom Shakespeare, Lennard Davis, Rosemarie Garland Thomson, entre otros, han consensuado en llamar como el "modelo médicorehabilitador", centrado específicamente en el problema individual que supone tener una limitación física y que impide el 
desarrollo de tareas y funciones cotidianas y laborales. Según Patricia Brogna este modelo privilegió "su aspecto individual, orgánico, corporal o funcional” (Brogna 161) e instaló una serie de saberes y conocimientos - provenientes del área de la cienciaque actuaron en función de las posibilidades de rehabilitación o curación de cuerpos clasificados como desviados, deformes y anormales. La discapacidad, desde su definición estrictamente médica, categoriza y estigmatiza de manera negativa las identidades de personas que exceden la categoría de la normalidad, entendida esta última como la condición de actuar con suficiencia y competencia frente a las demandas que una sociedad productiva -y comprometida con discursos de rendimiento y producción económica- precisa para su correcto y próspero funcionamiento.

Paralelamente, como han observado David Mitchell y Sharon Snyder, la discapacidad también se convirtió en el "tropo maestro de la descalificación humana" (3), lo cual significa que sirvió para desprestigiar las acciones políticas, artísticas y estéticas emanadas de cuerpos no normativos porque no se correspondían con una forma deseable y legible dentro de la producción cultural. De hecho, las representaciones sobre la discapacidad, siguiendo a Sunaura Taylor "are often born from medicalizationthe idea that disability is an issue best situed for the fields of medicine and rehabilitation" (42). Todo aquello que era manufacturado, creado, incluso, escrito por un sujeto con discapacidad era mirado bajo sospecha, descalificado por no considerarse arte y adjetivado como enfermizo, desviado o extraño. Sujetos patologizados y subalternizados fueron desacreditados como cuerpos "incapaces" de producir artefactos estéticos: la discapacidad funciona como un descalificador cultural, pero al tiempo, como sostiene Siebers, "disability, too, has to be disqualified" (Disability Aesthetics 24).

Desde la década del setenta del siglo pasado, específicamente en el hemisferio norte, se originó el modelo social de la discapacidad que, según Tom Shakespeare "has been called the big idea of the disability rights movement" (14). Su función principal consistió en eliminar las denotaciones medicalizadas que habían funcionado como única opción posible para explicar la situación particular de determinados cuerpos que resultaban excesivos a los estándares normativos. Este modelo postula que la deficiencia debe ser comprendida de manera correlacional con el 
contexto en el que esta se produce, dicho de otro modo, la discapacidad resulta no de un problema orgánico, sino de las barreras sociales que se les imponen a ciertos cuerpos para que estos no tengan las mismas posibilidades de acceso y participación que aquellos considerados "capaces" y normales. Las limitaciones, sin embargo, no solo son congénitas: también son adquiridas por las demandas del mercado global, la industria farmacéutica, el capacitismo, la injusticia ambiental, la expansión del imperialismo y la guerra, que producen cuerpos y mentes debilitados en sus nombres ${ }^{2}$.

De manera simultánea, una serie de activistas y académicos con discapacidad produjeron otras reflexiones en torno a su situación como cuerpos enfermados por la cultura y la historia. La aparición de los disability studies, un campo de conocimiento heterogéneo y crítico, instaló la necesidad de volver a interrogar los procesos históricos, sociales, económicos e ideológicos que le dieron forma a determinados saberes y prácticas originadas, especialmente, para actuar en función de un cuerpo denominado como excesivo, monstruoso e incapaz. El temprano proyecto de los estudios de la discapacidad, según Lennard Davis (1995) consistió en "desnarrativizar y desaburguesar" (25) la idea aspiracional de la discapacidad, tramada específicamente por una sociedad capacitista y normativa que legisla sobre el cuerpo diferente por encontrarlo insoportable e improductivo. Los reclamos y las demandas de agrupaciones y entidades colectivas con discapacidad, cohesionadas por sus intereses para reclamar una vida justa, independiente y autónoma, coincidió con la conformación de otras miradas a la discapacidad ya no como una categoría taxativa, sino como un fenómeno social, político y cultural desde el cual se construyeron nuevas posibilidades de enunciación, representación, resistencia y lucha política.

De igual manera, esos reclamos constantes cambiaron radicalmente los debates sobre la discapacidad en el siglo XX y promovieron otra manera de pensar las historias estereotipadas de sufrimiento, padecimiento, dolor e impunidad que habían ordenado sus interpretaciones por décadas. De una retórica

2 Esta idea la retomo a partir de los planteamientos que hace Jasbir Puar en su lúcido libro The Right To Maim. Debility, Capacity, Disability (2017), que aconsejo revisar. 
esencialista y médica, donde se admitía hablar de la discapacidad bajo términos como diagnóstico, pronóstico, cura o rehabilitación, comunidades políticamente articuladas transformaron estos códigos de enunciación y representación para desautorizar un lenguaje distanciado de las experiencias reales de cuerpos y mentes diferentes. La discapacidad, vista como signo de orgullo, lucha y politización, multiplicó identidades, interrelacionó luchas, gestó alianzas minoritarias y se abasteció de un conocimiento emanado de la misma consciencia encarnada de sus sujetos, como lo menciona Tobin Siebers: "The body is alive, which means that it is a capable of influencing and transforming social languages as they are capable of influencing and transforming it" (Disability Theory 68).

Si bien el panorama antes descrito se corresponde con las necesidades puntuales del Norte global -y solo hasta el año 2006 se firmó la Convención Internacional sobre los Derechos de las Personas con Discapacidad en la ONU a la que se suscribieron múltiples países latinoamericanos- en el contexto de estas álgidas y vitales discusiones se puede situar la producción autobiográfica y poética de Gabriela Brimmer desde América Latina. El primer esfuerzo de desarticulación cultural en torno a la discapacidad y sus retóricas medicalizadas se había llevado en cabo en las escrituras del yo, de las Gabriela participó, durante la década del setenta -aunque ya existían algunos antecedentes justamente en el terreno de la poesía y la autobiografía después de la primera guerra mundial, según Thomas Courser (2007)33-, justo durante la formación del modelo social en el hemisferio norte y con el nacimiento de redes de activismo y colaboración llevadas a cabo por sujetos con discapacidad. Gabriela produjo una consciencia política y situada sobre la parálisis cerebral, lo que le permitió construir un tipo de agencia particular que, desde mi perspectiva, cohesiona su proyecto como activista y sujeto femenino. El espacio conquistado de la escritura para Gabriela fue palmario: con él exploró la situación comunitaria de aquellos cuerpos que fueron diagnosticados con parálisis cerebral y sobre los cuales actuaron

3 Según Courser: "Yet one can see why autobiography is a particularly important form of life writing about disability: written from inside the experience in question, it involves self-representation by definition and thus offers the best-cas scenario for revaluation of that condition" (Disability, Life, Narrative 458). 
saberes arbitrarios a su propia experiencia, disminuyéndolos ontológicamente como pacientes. Así lo enuncia Gabriela:

Algo que me ha servido mucho a lo largo de mi existencia, es el estar bien consciente de las cosas que puedo hacer y de las que no, por ejemplo: sé que no puedo correr, pero con mi pensamiento puedo volar en fracción de segundos al más distante de los lugares; se me dificulta hablar, pero mis libros, mis cartas y mis poesías hablan mucho por mí; mis manos tal vez no puedan hacer una caricia y sin embargo he sabido amar como mujer, como madre y como amiga (Brimmer, Gabriela Brimmer 215).

Los primeros espacios de confección de significados "otros" sobre la parálisis cerebral, fueron concretados en la producción escrita de Gabriela. El impulso autobiográfico y la creación poética recuperaron $\mathrm{y}$ reinventaron su subjetividad medicalizada, redescubriendo así su carácter enteramente indócil al oponerse al dominio hospitalario, a los procesos tortuosos de rehabilitación y a las constantes negaciones sobre su agencia como sujeto de deseo. La escritura le permitió a Gabriela suturar los dolores dejados por la imposición médica y, desde ella, devino sujeto hablante. Más que una tramposa invención o un disimulo estratégico para (re)crear su vida, Gabriela acude a esa biografía herida o, como lo sostiene Susannah Mintz, una auto/body/graphy (23) (auto-corpo-bio-gafía), para gestar un despliegue narrativo, encarnado y decidido que desmantela un sistema de creencias y dominaciones, familiares, médicas, patriarcales, capacitistas, sexistas y segregadoras que perviven en la vida de las personas con discapacidades, pero también en tanto materia de indagación sobre la legitimidad de su existencia. La (auto)narrativización y la imaginación poética funcionaron como espacios de disenso en su voz autorial: ella misma acudió a una forma alternativa de enunciación que ensayó su proyecto político-estético contra las credenciales hegemónicas del conocimiento sobre la "enfermedad" que padeció. Los usos múltiples de la palabra descubren las intensidades afectivas de Gabriela: sus relaciones con el mundo, con el amor -no en tanto tema recurrente, sino como alimento vital de la existencia- y con los pliegues de una memoria alojada en el cuerpo. 
Rosemarie Garland Thomson afirma que la manera en que las personas con discapacidades han sido imaginadas y representadas en la cultura ha sido a través de la fotografía sobre freaks, las campañas de caridad, los retratos médicos y las representaciones espectaculares que, retóricamente, apelan a un pathos que conmueva, genere piedad o devuelva cierta esperanza normativa a quien encuentra en estos cuerpos una diferencia constatable: "These images portray disability narrowly as sensational, sentimental or pathological" (23). Existe un tráfico retórico que suspende las posibilidades de significación de un cuerpo que escapa a la norma y oscurece sus complejidades políticas, estéticas y afectivas. La condiciones de legibilidad de la discapacidad están controladas culturalmente por el estereotipo y el fetiche: sobre este cuerpo actúan discursos y se moldean de manera imaginarias experiencias, que en la mayoría de las ocasiones están divorciadas de las experiencias reales que viven personas con discapacidad; sus cuerpos son solo depósitos infinitos de metáforas y alegorías que no se corresponden con la situación particular de las formas de vida minoritaria, sino que representan en múltiples ocasiones "the image of the Other" (Siebers, Disability Theory 60); a saber, una otredad que, distante y necesaria, debe existir para confirmar el agónico dominio de la normalidad.

Esas formas tradicionales de nombrar y representar la discapacidad son descreditadas por Gabriela. Si la retórica funciona, siguiendo a Donna Haraway, como el acto de "persuasión que tienen los actores sociales importantes de que el conocimiento manufacturado que uno tiene es un camino hacia una forma deseada de poder objetivo" (316), en Gabriela se deshace a la luz de las demandas y alternativas que le ofrece la militancia político-afectiva en el terreno de la discapacidad. La retórica, no solo como disciplina encargada del estudio de las propiedades del discurso, sino como ejercicio del poder nombrar, decir y representar se ven intervenidas en las diferentes prácticas textuales de Gabriela, más específicamente, en la manera en que usa, tensiona y desautoriza la producción manuscrita para emplazar el pie-boca como génesis y principio de la enunciación poética y narrativa. Gabriela aniquila las imágenes inválidas, desposeídas, infantilizadas y triunfalistas que han servido cognitivamente para sostener un saber sobre el cuerpo diferente; es desde la creatividad emanada de ese cuerpo femenino no normativo, descalificado e 
injuriado, en que procede a elaborar una retórica diferente sobre su condición: una que se haga elocuente, carnal y extensa desde una experiencia corporal y situada.

En relación con lo anterior, la poesía de Gabriela se debate entre los rigores del ejercicio de poetización, que se correspondería, en términos formales, con el dominio de los recursos disponibles dentro la actividad poética, y con la experiencia que la interpela como sujeto y cuerpo. Gabriela menciona: "escribo poemas sin fijarme en reglas ni en rimas. En ellos saco mi coraje, desfogo mi rebeldía" (Brimmer-Poniatowska 11). Esta afirmación transforma las condiciones de evaluación e interpretabilidad de los objetos verbales escritos por Gaby: más que un conocimiento sobre la métrica -si es lo que según Gabriela no atiende cuando escribe dentro del género-, la voz, el deseo y el sentimiento cobran protagonismo, son lo que importa ser transferido, hecho acontecimiento poético y vital. La versificación convive al tiempo con una necesidad de gestionar las intensidades del afecto que recorren el cuerpo. La poesía mapea elocuentemente el cuerpo y el cuerpo es la geografía experiencial desde la cual escribe Gabriela. La poesía como ejercicio de iluminación, no por una vía mística, sino corporal; la poesía como necesidad, aspiración y sustento. Gabriela escribe:

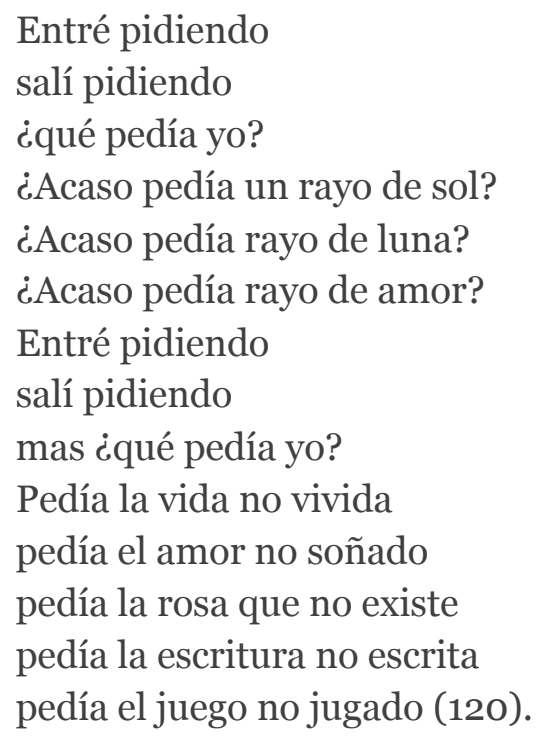

La mayor parte de los hablantes poéticos que inventa Gabriela están construidos a través de constantes oraciones interrogativas que, más que albergar la posibilidad de la respuesta, 
construyen la urgencia del cuestionamiento: un derecho a expresar la voluntad y la acción de una palabra que sugiere y reclama, solicita y desactiva cualquier lugar común reservado a una voz y, por tanto, a un cuerpo, que pareciera no tener nada para decir.

James C. Cherney (2011) en "The Rhetoric of Ableism" arguye que la retórica, vista como ejercicio discursivo del poder y la ideología son unas aliadas convenientes de una cultura que entroniza la capacidad como promesa exitosa de relación con el mundo: "ableism is that most insidious form of rhetoric that has become reified and so widely accepted as common sense that it denies its own rhetoricity-it "goes without saying"' (8). Las maneras en que están figurados, representados y dichos los cuerpos con discapacidades en las sociedades contemporáneas están alejadas de su realidad y experiencia y esto genera marcos de conocimiento instalados en la cultura que no se pueden evitar. La retórica norma y formula una verdad que orienta nuestra cognición desde el lenguaje sobre el mundo. Gabriela se separa, y en consecuencia, rechaza esos modelos normativos que constriñen su capacidad expresiva; ella rehace y remueve las normas de la lengua para aparecer públicamente como sujeto de discurso, empleando una variedad de recursos que deben ser examinados como respuestas contra-culturales y contrahegemónicas desde la discapacidad.

\section{Los poemas del pie-boca}

Byung-Chul Han (2017), en su diálogo con Paul Celan y Peter Handke, afirma que "el poema es un acontecimiento dialógico" (103), un espacio que permite la conjunción y la reunión entre un yo y un tú, relación que se ve amenazada constantemente por el espacio de la comunicación digital, donde el otro no interesa como invocación, sino como cercanía cada vez más difusa. Sin embargo, el filósofo coreano llama la atención sobre el arte y el poder de la poesía como una instancia conversacional, cuyo objeto es la atención al "descubrimiento del tiempo de lo distinto" (103); a saber, una manera de tener consciencia del otro para construir un horizonte de relación que supone reconocerlo, devolverle su lugar como prójimo. La poesía y, por tanto, el arte, están en el camino hacia lo distinto, hacia el extrañamiento del mundo, hacia aquello que debe hablarse en nombre de una causa 
que no nos pertenece, pero irremediablemente nos aboca. Ahora bien, ¿̇cuál es la función política de los poemas de Gabriela?, ¿qué relevancia tiene su imaginación poética?, ¿de qué manera Gabriela complejiza las condiciones materiales de la actividad poética para producir un registro "otro" de su experiencia?, ¿qué figuraciones e imágenes introduce Brimmer a la luz de su experiencia como sujeto femenino de la experiencia?

Para proceder con un breve examen de algunos poemas recopilados de los libros de los cuales me ocupo en este artículo, voy a proponer tres categorías temáticas: los afectos; el amor y la sexualidad; y la voz política. Estos grupos temáticos orientarán el análisis que propongo como ejercicio de inspección a una formación retórica hecha posible desde la experiencia de la discapacidad en Gabriela que se alía, específicamente, con su autobiografía. Quiero entender la poesía, en este sentido, como una de las modalidades de agencia que Gabriela ensayó y que señaló de manera constante durante la narración de su vida. La poesía no como ejercicio menor o como cultivo de una sensibilidad inspiracional, sino como una labor cuidadosa y politizable donde ella ejerce su legítimo derecho a aparecer. Por ejemplo, "En una playa de letras", poema perteneciente a Gaby. Un año después, el sujeto poético invoca el espacio de la escritura como anhelo y deseo. No es casual que la invocación a la letra y a su poder articulador, pero también testimonial, sea el objeto de interés del sujeto lírico: "Arena de letras/ ando buscando/para hacer mis poemas/y para decir sencillamente/lo que vivo" (45). La escritura se prefigura como una búsqueda que, en su urgencia, diagrama un porvenir distinto para esta voz poética. El derecho a aparecer, que Butler ha examinado como una respuesta política frente a los mandatos de la precariedad en contextos neoliberales cada vez más entregados a la disolución y segregación de las vidas minoritarias, es tensionado en Gabriela a la luz de la búsqueda de otros medios para accionar corporalmente la conquista de un espacio de enunciación. La palabra funciona en cuanto un vector de movilización del pensamiento $\mathrm{y}$, por consiguiente, de la acción: escribir y pensar aspiran a ser las posesiones más preciadas del hablante.

Es preciso advertir que el proyecto escritural de Gabriela en un amplio sentido - pues no hay que olvidar que cultivó el diario íntimo, la poesía, la carta, el artículo periodístico- es una 
actividad vital y necesaria. Las jornadas de escritura ocuparon alrededor de tres o cuatro horas de la vida cotidiana de Gaby y fueron determinantes en la construcción de una autoría que contó con la participación y complicidad del cuerpo en su proceso, tal como comenta Elena Poniatowska, en el prólogo de la autobiografía: "Gaby teclea cinco o seis cuartillas, letra por letra, con el dedo gordo del pie izquierdo. Ante mi admiración exclama: "No soy heroica es la vida la que me empuja" (Brimmer-Poniatowska 16)4. La autoría de Gabriela se hará con el pie izquierdo, de hecho, es el pie el origen de una vibrante experiencia poético-corporal. De acuerdo con Gabriela García Hubard, la plasticidad de una autora se da "a través de una complicidad entre corpus-cuerpo, simbólico y biológico" (285), lo cual complica mucho más la manera en que se encarna una autoría a través de las condiciones materiales del cuerpo, extensibles, por supuesto, a los objetos estéticos producidos. Los momentos de escritura, composición, corrección, edición, entre otros, llevadas a cabo con el pie complejizan materialmente la acción poética y autorial, lo cual significa que iluminan otra área de la producción de una imagen de autor que debería ser examinada bajo las condiciones materiales de cuerpos que escapan a la sospechosa regla canónica y universal. No es el poeta que escribe de pie, como bien sabemos por la experiencia de Virginia Woolf, Vladimir Nabokov o Ernest Hemingway: es la poeta que escribe con los pies, que abandona la manualidad del trabajo de la escritura.

Ahora bien, varios poemas de Gabriela están vinculados de manera inextricable con los afectos. Me gustaría detenerme en algunas imágenes de estos poemas que establecen, a mi modo de ver, una relación cercana entre la experiencia que viven los sujetos hablantes y la experiencia de Gaby. Si como mencioné en líneas anteriores, el poema es un texto dialógico, este diálogo se concretiza a través de la experiencia encarnada del sujeto autoral. Ahora bien, la experiencia se vierte en la actividad poética y define, al menos si leemos la poesía y la autobiografía en esa clave, la intensidad heteróclita de la subjetividad que nos interpela como lectores. La textura afectiva que recorre los poemas del pieboca deja entrever aquello que los hablantes poéticos son capaces de nombrar en virtud de presentarse como sujetos

4 Gabriela desarrolló una desviación en su columna conocida como escoliosis por las intensas jornadas de escritura. 
experienciales, apelando, o mejor, construyendo una empatía directa con su lector: "Quisiera que ustedes comprendieran/que soy como los demás, un magma de amores, pasiones, enojos, deseos, defectos y cualidades/que anhela encontrar paz" (BrimmerPoniatowska 74).

Las interpelaciones constantes a un otro son motivo de necesidad de la voz poética, un dar cuenta de lo que sucede en su interior, y que solo es comunicable siempre y cuando la palabra que llega haga posible tal acontecimiento. Esa presentación del sujeto hablante es al tiempo una estrategia de confrontación: la voz que habla mapea las intensidades del afecto que recorren el cuerpo: "Dejadme sufrir a mi modo, /dejadme/Dejadme que ame a quien quiera, /dejadme" (81). La corporalización del dolor, la soledad y la incertidumbre son las variadas formas que tienen los hablantes poéticos producidos por Gaby para insistir en que todo pasa por el cuerpo como eje central de la experiencia. El afecto no es solo expresión de soledad, dolor, resentimiento o deseo; es, por el contrario, la capacidad de impactar y apelar retóricamente a un interlocutor. El afecto, según Brian Massumi -en su diálogo con Spinoza-, es "an ability to affect and be affected" (15), lo cual significa que todo aquello que expresa la voz poética se hace explícito para impactar y dejarse afectar: entregar el material para que este sea leído como un riesgo de apertura.

Huelga decir que la cohesión de estos textos está articulada a la consciencia sobre la vida; su celebración convive con el dolor de la pérdida del padre y el amado -de hecho, hay algunos poemas que los traen de vuelta para imaginarlos, establecer un diálogo con ellos o increparlos por su ausencia-, pero en ningún caso la experiencia se vuelve un lamento o una agonía que embarga las posibilidades de seguir estando viva. La vida vuelta un acontecimiento de manera contundente le permite a Gaby morar el mundo a través de la poesía. El deseo por otro, la necesidad de sentirse amada, las sensaciones corporales dejadas por el amor y el canto a la vida despliegan un impulso creativo desde donde emerge su corazón errabundo. La experiencia poética afirma, confirma y reafirma al sujeto material de la experiencia: la palabra no oblitera sus sentidos, por el contrario, amplía el radio de sus posibilidades y, al mismo tiempo, el poema es apertura y ansia, espera y paciencia: 
Viviré.

Te espero tiempo.

Te espero risa.

Te espero amor.

Te espero odio.

Te espero venganza.

Te espero calma.

Te espero vejez.

Te espero muerte.

Te espero vida (158).

Por otro lado, hay un conjunto de poemas que aluden de manera diversa y multánime al amor y a la sexualidad, principalmente, inspiradas en la experiencia de Gaby como sujeto de deseo. Esta modalidad de agencia, en términos sexo-afectivos, otorga a Gabriela autoridad y control sobre la arquitectura de sus sentimientos. Según Tobin Siebers, "disabled sexuality not only changes the erotics of the body, Vahldieck implies, but also transforms the temporality of lovemaking" (Sex and Disability 48), es decir, transforma las posibilidades de ejercer un derecho a ser sexuado y a sentir placer que no deben pasar por los circuitos normativos y heterosexistas de la penetración-eyaculación. Las posibilidades de erotizar el cuerpo son múltiples y atienden más a una necesidad de dejar que el placer recorra el cuerpo y no sea solo el telos de un encuentro con el otro. En este sentido, no se pueden entender algunos de sus poemas como inocentes invocaciones: eso sería infantilizar de nuevo su deseo. Hay una fuerza vital y claramente política en la voz poética de Gabriela cuando confronta, desafía y corrige los imaginarios en torno a ejercer su derecho a amar y a ser amada. Esa alma herida, a la cual alude en su autobiografía, mapea las intensidades del deseo y no se resigna a la convencional desexualización vinculada a las personas con discapacidad. Ella menciona: "Sé que soy mujer, he tenido orgasmos, mis deseos son tan fuertes que una sola caricia basta para provocar en mí un orgasmo, los tengo también cuando duermo, pero soy joven para conformarme con sólo eso; sólo el amor a medias, nunca la plenitud" (Brimmer-Poniatowska 176).

Gabriela rechaza su reducción como sujeto de deseo, en cambio, propone desafiar, a través de la poesía, las convenciones morales de su condición como mujer con parálisis cerebral. Bien es sabido que las personas con discapacidad han sido además de 
patologizadas, desexualizadas e infantilizadas, como si su deseo debiera ocultarse para no escandalizar a nadie. Gaby desafía subversivamente las reglas de una "no-sexualidad" que es el lugar reservado a corporalidades no normativas, en cambio, propone tensar y discutir, desde sus poemas, esa necesidad de verbalizar el deseo más allá de las coordenadas morales y represivas que niegan su derecho: "Te tengo/más no te siento/te conozco/muy poco/y por más esfuerzos/no penetro. /Tú no me has penetrado" (177). "Tu no me has penetrado", que se repite cuatro veces en el poema antes citado, funciona en un doble sentido, aunque no deja lugar a una ambigüedad interpretativa. La penetración, en este caso, es afectiva, pero también carnal. En un plano imaginario, el sujeto lírico envía su mensaje y activa la repetición como evidencia incuestionable de lo que es capaz de nombrar y elevar en el poema en virtud de hacerlo digno.

Luis y Quique, por ejemplo, aparecen en la autobiografía de Gabriela. Ella menciona en diversas ocasiones cómo se enamoró de ellos y cómo encuentra una motivación lírica: "Me he enamorado no una, sino muchas veces" (167), manifiesta Gaby. Y esa consciencia sobre el amor, que no se la arrebató nadie, es el acto de desobediencia e indocilidad más potente que expresó a través de la escritura. Empero, el proyecto amoroso no está circunscrito a una idealización corrosiva y dañina y que solo podría constituir la regla del conocimiento amoroso: la decepción, el fracaso, la falla, la no correspondencia también se asoman en los poemas: "La vida reparte/peligros, amarguras, /dolores y amor. /Toma de ella lo que te plazca/y déjame a mí en paz/que el amor que te di/te lo voy a quitar" (178). El sujeto reconoce la imposibilidad de la concreción del amor romántico e ideal, en cambio, propone desde un agudo lamento, pero también en una transparencia envidiable, asumir que amar también es no poder hacerlo y, sobre todo, de reclamar el derecho de dar amor y asimismo de retirarlo. Por ejemplo, en "Mar Muévete", el sujeto lírico solicita y ordena al mar que arrastre y se lleve el mal, el daño y la decepción. Esa invocación patética, en cuanto forma de conmoción provocada por el dolor de la decepción, se vuelve fundamental en el poema. La súplica de la voz poética convive con el ansia del movimiento y la urgencia para encontrar afecto: "Mar muévete/y trae un cariño para mí. /Tus olas son mi barco/llévame en pos de ti/para buscar un cariño" (Brimmer 17). 
El conocimiento amoroso de Gaby, como lo mencioné en líneas anteriores, no solo es un asunto de inocencia, más bien, deviene de un combate con las limitaciones del mismo lenguaje. De acuerdo con Roland Barthes:

querer escribir sobre el amor es afrontar el embrollo del lenguaje: esa región de enloquecimiento donde el lenguaje es a la vez demasiado y demasiado poco, excesivo (por la expansión limitada del yo, por la sumersión emotiva) y pobre (por los códigos sobre los que el amor lo doblega y lo aplana) (121).

Frente a las vicisitudes de esos códigos de la lengua para referir, nombrar y conjurar el amor, pero también para darle un lugar a la pulsión del eros y el deseo en su escritura, Gaby amplía los repertorios retóricos de la actividad poética para encontrar genuinamente una voz que le haga justicia a su sentir y que se corresponda con su experiencia como mujer sexuada. El trabajo metafórico de Gaby, hecho posible por el pie-boca, le garantiza una disponibilidad de imágenes muy distinta para centrar, de nuevo, su saber singular y político sobre el cuerpo, los afectos y la sexualidad: "El amor se parece exactamente a mí/su sombra es mi presencia/su gemido alimenta mi ser;/andamos y deshacemos el mismo camino" (Brimmer 93).

Por último, hay un conjunto de poemas vinculados con la militancia encarnada de Gaby. En este sentido, la poesía repiensa la función de la voz poética en aras de entregarle un mayor compromiso de libertad en relación con su formación como sujeto político: "cuerpo y escritura se funden para aparecer, no solo en la esfera pública o editorial, sino como acción corporeizada que critica un sistema de exclusión de aquellos cuerpos que deberían integrar una comunidad corporal 'normal' y sana" (Ayram 4). Si los afectos, el amor y la sexualidad se politizan, también debe serlo el mundo que siente y atraviesa el cuerpo de Gabriela. Su formación marxista, heredada de su padre, será fundamental para que los poemas del pie-boca y la vida narrada puedan coexistir en el plano de una acción corporeizada, siguiendo a Butler, acción que, mediada por un apoyo tecnológico, en este caso la máquina de escribir, sean los instrumentos decisivos del posicionamiento de Gabriela frente al mundo. Las desapariciones estudiantiles en la dolorosa noche de Tlatelolco en el 68, Dios como imagen imputable, la vida del Che Guevara y Camilo Torres y la 
situación que viven personas con parálisis cerebral en su cotidianidad son todos temas de gran interés para Gabriela.

¿Qué es realmente lo político en la escritura poética en Gabriela Brimmer? Siguiendo a Jacques Rancière, la política es un ejercicio de permanente desacuerdo: "la esencia de la política es el disenso" (Rancière Política, policía, democracia 73). Solo donde el desacuerdo revela y desmiente la ficción rectora de la igualdad, la política aparece como urgencia para aquellos "incontados" que no tienen acceso a la palabra y a la expresión pública o definitivamente están expulsados por no encarnar el ideal de sujeto político que reclama un proyecto nacional inspirado en el modelo policial, orden de dominación en el reparto de lo sensible: "El trabajo esencial de la política es la configuración del espacio propio" (Rancière Política y democracia 71). La conquista de la palabra y de sus posibilidades de expresión rearticula a Gaby como mujer, activista y cuerpo: el discurso que ejerce Gabriela desacata y desobedece, primero, su mandato como cuerpo paralizado, enfermo y rehabilitable; segundo, su no-lugar como sujeto de derecho y deseo; y tercero, su participación como creadora en el campo cultural mexicano. El lugar de lo político en Gaby es precisamente su autoconstrucción narrativa y poética: más que máscaras autoriales o posicionamientos desconectados de la realidad vivida, la paciencia y dedicación de la escritura, hecha desde un amenazante y productivo "margen" -la institución, el hospital, el centro de rehabilitación, el espacio doméstico-, logran construir su agencia política, entendida como "una práctica transformadora para desarrollar otras formas no hegemónicas de enunciación de la subjetividad desde lo colectivo" (Villaplana 19).

La voz de Gaby es contestataria y exige inusuales formas de justicias desde su experiencia como activista. Por ejemplo, frente a la masacre de Tlatelolco, Gabriela todavía se resiste a olvidar este evento traumático en la historia nacional y vuelve, desde la poesía, a interrogar y cuestionar semejante acto de inhumanidad: "Tlatelolco, ciudad azteca/nunca podremos olvidar. /No, yo no me voy a callar/y siempre repetiré/que la masacre en Tlatelolco, / es ejemplo de inhumanidad" (130). El poema convoca un nosotros herido y vituperado para emplazar la escritura como un acto testimonial y al tiempo, hacerla partícipe de la historia: no olvidar los daños que dejó en la memoria colectiva. La escritura sirve como un medio de denuncia e interpela a un lector 
para que este no pueda pasar por alto el pasado reciente. La posición de Gabriela es radical respecto a Tlatelolco: las muertes habrá que vengarlas. La arenga que produce el poema también se convierte en una diatriba que socava la memoria oficial.

\author{
¿Culpables? No hay más que uno \\ la verdad no se puede ocultar \\ fue el gobierno asesino \\ que loco mandó matar \\ a estudiantes, adultos y niños \\ que fueron a Tlatelolco \\ a exigir al gobierno \\ un poco de libertad. \\ Tlatelolco significa muerte \\ y muerte que hay que vengar (130-1).
}

Gaby lee severa y críticamente el panorama político mexicano y busca formas inéditas de alianza y empatía con otras minorías, como con los estudiantes. En este sentido, cabe aclarar que "dar cuenta de uno mismo es contar una historia del yo, en efecto, pero es también, sobre todo, y por lo mismo, contar una historia del tú" (Rivera Garza 63). Contra la modalidad discursiva del panfleto, la escritura poética también deja entrever su resentimiento en un doble sentido: de volver a sentir, de hacerlo pasar por el cuerpo, pero también como molestia y desacuerdo con las políticas estatales y represivas que sacrifican y desaparecen vidas consideradas reductibles y prescindibles: "El gobierno se ensordece/ante este grito/y sólo hay una verdad:/que en México no hay/libertad./El arma del estudiante/es la razón/y no los fusiles/que el gobierno empuña/para matar" (138).

Finalmente, en "Padre nuestro", la letanía a Dios tiene una interferencia política que reemplaza la súplica por el diálogo. Varios poemas tienen a Dios como centro de la reflexión: a él se acude, a él se le habla, con él se habla. En todo caso, no es una poesía religiosa la que escribe Gabriela, pero sí dota de un valor incuestionable la presencia difusa y escurridiza de Dios. Principalmente en este poema el sujeto lírico menciona: "repitiendo: santificado sea tu nombre/Y es aquí donde paro, en la tierra como en el cielo. / La tierra está siempre dividida en dos:/Poseedores y poseídos, represores y reprimidos/malos y buenos para acabar pronto" (Brimmer 106). La oración se paraliza y se 
complica cuando a Dios hay que hacerle ver que la tierra está divida. La voz poética exhibe un conocimiento que tal vez a la figura eterna del Dios judeocristiano se le ha olvidado reconocer. La voz increpa a la figura celestial y convierte el espacio de la oración, usualmente considerado de comunión, en un acto de disenso: "iPadre nuestro, /llámate como te llames! /Yavé, Jesús, Krishna, Buda, /ióyeme! te hablo de tú por tú,/como viejos amigos./Viejos conocidos que sabemos/la historia de] mundo" (106). La confrontación se hace desde una consciencia de clase o al menos desde una consciencia sobre la lucha histórica de las clases, lección marxista indiscutible para pensar en las variadas formas de desigualdad y precarización de la vida humana. Al Dios de las alturas una voz paralizada -objeto de caridad en el texto bíblicolo encara y confronta: "y no digamos sumisamente: «Hágase su voluntad»" (Brimmer 106).

\section{Discapacidad como saber alternativo}

De acuerdo con David Mitchell y Sharon Snyder (1997), las escrituras autobiográficas escritas por personas con discapacidad durante la segunda mitad del siglo XX cumplieron una función decisiva en la construcción de otras representaciones sobre la diferencia corporal lejos de una imaginería médica y, por tanto, medicalizada de la vida: "The autobiographical narrator also provides a glimpse at a unique subjectivity that evolves out of the experience of disability as a physical, cognitive, and social phenomenon" (9). El cambio de focalización fue palmario dentro de los materiales literarios que orbitaron en torno a un "yo rasgado" que dejaba entrever un "espacio privilegiado de inquisición sobre la condición humana” (Cánovas 15). De otro lado, la eclosión de este tipo de escrituras también se opuso a una tradición de representación dentro de los lenguajes artísticos, específicamente en la literatura, que por siglos había ocupado el cuerpo no normativo como marca diacrítica de la diferencia. Las escrituras y producciones artísticas de personas con discapacidad se opusieron a las formas dominantes de representación que, en numerosas ocasiones, dejaban por fuera las complejidades éticas implicadas en sus disímiles experiencias.

La escritura autobiográfica, desde esta perspectiva, cambió radicalmente las miradas en torno a la discapacidad como 
una tragedia individual, en cambio, propuso, dentro de su programa narrativo, construir una autoridad ontológica que confirió dignidad, agencia y aparición política a vidas minoritarias que no debían ser entendidas como una asunto médico o patológico. Las escrituras del yo o, como lo ha denominado y estudiado Thomas Courser (1992;1997), "disabilility life writting”, efectuaron otros procedimientos de representación fuera de la hegemonía discursiva médica y actuaron activamente en la construcción y reconstrucción persistente de narrativas y saberes situados más allá de estrictos cuadros clínicos, en ocasiones, reducidos a meros espectáculos triunfalistas o a estériles muestras de autosuperación y milagro. Desde la discapacidad se produjeron múltiples experiencias escritas y, por ende, políticas, que llamaron la atención sobre lo que es posible engendrar, crear, gestar y producir desde una condición históricamente descalificada.

Ahora bien, el proyecto autobiográfico, pero también poético que emprendió Gabriela Brimmer a finales de la década del setenta, en primer lugar, generó la constitución de una experiencia encarnada que rindió testimonio y entregó nuevas coordenadas políticas sobre la discapacidad que desahuciaron los saberes hegemónicos que actuaron históricamente sobre corporalidades no normativas, desligándose de un programa de gestión y administración sobre la vida. Gaby se autoconstruyó como sujeto y, al tiempo, creó un cuerpo textual, al decir de Amy Kaminsky, que le otorgó posibilidades discursivas y subversivas donde cupo como sujeto mujer y cuerpo deseante: "the ability to express herself textually means for Gaby the world's acknowledgment of her presence. By creating the textual body that is the book, the physical body can be transcended" (62). Llama la atención, en este sentido, que si bien existe un testimonio sobre la vida de Gaby y en ella se estampan las historias de opresión que logró desafiar constantemente, la autobiografía y el libro de poemas no fueron escritos y pensados como materiales didácticos, morales o inspiraciones sobre la lucha triunfalista de Gabriela, antes bien, fueron con posterioridad relegados a una esfera de la autosuperación en el periodo, sin antes pensar en la agencia particular que ella construyó y logró llevar a cabo con su pie-boca. La poesía y la autobiografía -esta última más próspera en términos de recepción cultural- deben ser pensadas como objetos 
estéticos que guardan toda la densidad y potencia de un archivo sobre la diferencia corporal que no puede ser ignorado.

En segundo lugar, el espacio de la escritura promovió un régimen representacional muy diferente sobre la parálisis cerebral, desacreditando absolutamente el sospechoso lugar común de que estos cuerpos "diagnosticados", por tanto, medicalizados, no tenían derecho a ser legibles como sujetos y a ser imaginados como parte de una comunidad de experiencia. Gabriela dota de un valor resistente y vibrante a sus escrituras, las colma de un saber que solo pudo haber conquistado, producido y desarrollado por la opresión a la que fue sometida. Desde ese modo particular de sentir y pensar, la discapacidad no es motivo de vergüenza, sino una marca de orgullo que recorre la escritura de Gabriela. La autobiografía y la poesía producen unas condiciones de legibilidad muy diferentes sobre su cuerpo e irradian de significado las acciones corporeizadas y alternativas que propuso para narrarse a sí misma y, al tiempo, narrar a otras vidas minoritarias que también tuvieron derecho a ser reconocidas: su madre, su nana/cuidadora, sus compañeros de reclusión, que bien podrían ser valoradas y enmarcadas como relaciones de interdependencia y coalición corporal registradas en la escritura. Robert McRuer nos recuerda que la interdependencia es "encounters alternative public spheres expose the inadequate of the able-bodies/heterosexual family" (101), y esos encuentros son posibles por el nivel de reciprocidad que gestan las relaciones alternativas opuestas a un modelo de rendimiento corporal y sexual y a una constitución convencional de familiaridad. De hecho, Gaby ejerció su derecho a la maternidad cuando adoptó a Alma Florencia, su hija, y desde allí articuló una serie de prácticas de cuidado junto con su madre y su cuidadora para educarla. De acuerdo con Judith Butler, la interdependencia, desde un punto de vista ético, pugnaría por conectarse con la igualdad y "habrá que hacerlo de una forma que resulte perturbadora para los propios poderes que distribuyen reconocimiento de manera diferenciada o que altere su propia intervención" (49). La interdependencia como una trama tejida entre cuerpos, alianzas y afectos no solo es rastreable por la arquitectura de la obra autobiográfica, sino por la manera en que esta se corresponde con las relaciones de solidaridad y comunión que expresan los sujetos implicados. 
En tercer lugar, la escritura poética y autobiográfica de Gabriela avanza en un plano muy interesante: la retórica. Como mencioné anteriormente, la calidad de usuaria de la lengua no es suficiente para declarar una agencia potente en Gabriela, sino en realidad cómo tensiona las condiciones de producción discursiva para emplazar afectos, ideas y posiciones políticas con el pieboca, lo cual despierta un registro "otro" muy distinto de la experiencia. Gabriela participó como sujeto de discurso y no se reconoció dentro del lexicón clínico que la había definido desde los tres días de su diagnóstico: su propósito particular fue elaborar -con la conciencia de las posibilidades y extensiones de su cuerpo- un saber propio del lenguaje que hizo justicia a lo que realmente ella, en tanto sujeto mujer, pudo decir y nombrar. La poesía abona otro terreno de construcción de imágenes que restituyen los valores políticos a una vida minoritaria, es decir, le devuelve el control y la autoridad a un sujeto censurado. George Didi-Huberman observa que es "necesario instituir los restos: tomar de las instituciones lo que no quieren mostrar -lo residual, lo rechazado, las imágenes olvidadas o censuradas- para devolverlo a los que no tienen derecho, es decir, al 'público', a la comunidad de ciudadanos" (Devolver una imagen 223), y Gabriela, en el corazón de dichas instituciones, expulsa aquello que la margina para vivir y, en consecuencia, sale a través de la escritura, devolviendo aquellas imágenes que aún hoy sobreviven al paso del tiempo, duran como destellos y signos de supervivencia porque lo político "no puede prescindir, en uno u otro momento, de la facultad de imaginar" (Didi-Huberman Supervivencia 46).

Michael Northen en Beauty Is a Verb examina la emergencia y consolidación de una poesía de la discapacidad en cuanto género literario y autónomo en la tradición poética norteamericana. Según el autor, posterior a la constitución de The Independent Living Movement en la década del setenta y durante la aparición de American with Disabilities durante los años 90, se publican las primeras antologías coordinadas por Vassar Miller y Marsha Saxton y poemarios de autores/as con discapacidad como Karen Fisher, Kenny Fries, Stephen Kuusisto o Jim Ferris, quienes van a conformar el género en cuestión. La poesía en estos periodos se desarrolló como una respuesta política, estética y afectiva que esquivó las imágenes milagrosas, inspiradoras, trágicas, autocompasivas e indulgentes que estuvieron vinculadas 
históricamente a los sujetos con discapacidad y, al mismo tiempo, permitió a su autores/as desarrollar una consciencia poética alternativa en tanto manifiesto político del cuerpo discapacitado.

Si bien la preocupación de Northen en su breve historia de una poesía de la discapacidad es aplicable al contexto anglosajón -y hoy no hay una historia de la literatura de la discapacidad en América Latina-, es interesante observar cómo las técnicas de escritura poética elaboradas por estos autores/as comparten un vínculo común con las estrategias que usó Gabriela Brimmer para construir su agencia política y autorial. Brimmer desafió estereotipos, tensionó la lengua, reinventó la labor manuscrita y prestó el cuerpo para el proceso de producción escrita. Jim Ferris formula y discute la categoría Crip Poetry como el centro de la experiencia de poetas con discapacidad y su posibilidad para ser leídos y reconocidos bajo sus propios términos: "crip poetry carries in it the potential for an even more radical transformation - a transformation in consciousness, not only the consciousness of the poet and the reader, but the potential to transform the world" (1). Si bien a Gabriela Brimmer no podríamos encuadrarla dentro de una tradición crip propiamente anglosajona, sí pudo haber desarrollado una consciencia poética durante su vida en la que había comenzado por usar la escritura para trazar su disidencia corporal y hacerse legible en cuanto subjetividad minoritaria.

¿Por qué es posible afirmar que la discapacidad es un saber alternativo?, ¿de qué manera Gaby logra posicionar la poesía dentro de los marcos de ese tipo de saber particular? Si la descalificación, siguiendo a Tobin Siebers, es "as a symbolic process [that]remove individuals from the rank of quality human beings, putting them a risk of unequal treatment, bodily harm, and death" (Disability Aesthetics 23), Gabriela aprovecha su doble descalificación como sujeto mujer y cuerpo para producir desde allí un saber particular, situado y encarnado, en palabras de Donna Haraway, que hace que pueda hablar con una autoridad que solo ha sido posible construir en el devenir de su experiencia. La poesía en este sentido no es otra cosa que una modalidad de este saber que no colabora más con la idea culturalmente asumida de un arte inferior o terapéutico que es producido por un cuerpo no normativo. La poesía es un ejercicio de conciliación entre la sensibilidad y el cuerpo que la produce: de ahí que no 
podamos evitar la insoslayable certeza de cómo fueron producidos estos poemas, no porque parezcan "asombrosos" o "increíbles", sino por las condiciones materiales en que fueron escritos. Habrá que considerar que la poesía, enquistada en el cuerpo de la autobiografía, bien sea por decisión editorial como por deseo y voluntad de su autora, pueda ser entendida como un espacio menos lúdico y más político donde el pie-boca trabaja con un arsenal metafórico que se condice con su experiencia. Como menciona la misma Gaby: "Me gustaría poder decir en el final/que estuve agradecida/de poder ver, oír, oler, gustar y palpar/ante todo, y a pesar de todo/desde este cuerpo inhábil/Y esta silla de ruedas/ haber podido amar y razonar" (184).

\section{Bibliografía}

Antebi, Susan. Carnal Inscriptions. Spanish / American Narratives of Corporeal Difference and Disability. New York, Palgrave Macmillan, 2009.

Ayram, Carlos. "Hacerse un cuerpo a través de la palabra. Gaby Brimmer: discapacidad, enfermedad y escritura". Actas de las I jornadas internacionales cuerpo y violencia en la literatura y las artes visuales contemporáneas, Alicia Montes (ed.), Buenos Aires, Universidad de Buenos Aires, 2017, pp. $1-15$.

Barthes, Roland. Fragmentos de un discurso amoroso. Madrid, Siglo XXI, 1998.

Northen, Michael. "A Short History of American Disability Poetry". Beauty is a Verb. The New Poetry of Disability. Jennifer Bartlet, Sheila Black, and Michael Northen (eds.), El Paso, Cinco Puntos Press, 2011, pp. 31-45.

Brimmer, Gabriela. "Gabriela Brimmer por Gabriela Brimmer”. Ethos Educativo, n. ${ }^{0}$ 41, 2008, pp. 211-215.

Brimmer, Gabriela. Un año después. México D.F., Grijalbo 1980. 
Brimmer, Gabriela y Poniatowska, Elena. Gaby Brimmer. México D.F., Grijalbo, 1979.

Brogna, Patricia. "Las representaciones de la discapacidad: vigencias del pasado en las estructuras sociales presentes". Visiones y revisiones de la discapacidad, Patricia Brogna (ed.), Ciudad de México, Fondo de Cultura Económica, 2009, pp. 157-187.

Butler, Judith. Cuerpos aliados y lucha política. Hacia una teoría performativa de la asamblea. Bogotá, Paidós, 2017.

Cánovas, Rodrigo. Escenas autobiográficas chilenas. Santiago de Chile, Ediciones UC, 2019.

Catrileo, Daniela. Río herido. Santiago de Chile, Edicola, 2016.

Cherney, James L. "The Rhetoric of Ableism”. Disabled Studies Quarterly, vol. 31, n. ${ }^{0}$ 3, 2011, pp. 1-25.

Couser, Thomas. "Disability, Life Narrative, and Representation". The Disability Studies Reader, Lennard Davis (ed.), New York, Routledge, 2013, pp. 456-459.

Davis, Lennard. Enforcing Normalcy. Disability, Deafness and the Body. New York/London, Verso, 1995.

Didi-Huberman, George. "Devolver una imagen". Pensar la imagen, Emanuel Alloda (ed.), Santiago de Chile, Ediciones Metales Pesados, 2020.

Didi-Huberman, George. Supervivencia de las luciérnagas. Madrid, Abada Editores, 2012.

Ferris, Jim. "Crip Poetry, or How I Learned to Love the Limp". Wordgathering: A Journal of Disability Poetry and Literature. Issue 2, 2017. Disponible en: https://wordgathering.syr.edu/past_issues/issue2/essay/ferris.html. 
García Hubard, Gabriela. "De la deconstrucción del autor a la plasticidad de la autora”. ¿Qué es una autora?, Aína Pérez Fondevila y Mari Torras Francés (eds.), Barcelona, Icaria, 2019, pp. 265-290.

Garland-Thomson, Rosemarie. "Picturing People with Disabilities. Classical Portraiture as Reconstructive Narrative". Re-presenting Disability. Activism and Agency in the Museum, Richard Sandell, Jocelynn Dodd y Romsery GarlandThomson (eds.), New York, Routledge, 2010, pp. 23-40.

Haraway, Donna. Ciencia, cyborgs y mujeres. La reinvención de la naturaleza. Madrid, Ediciones Cátedra-Feminismos, 1995.

Han, Byung-Chul. La expulsión de lo distinto. Madrid, Herder, 2017.

Jörgensen, Beth E. "Negotiating the Geographies of Exclusion and Access Life Writing by Gabriela Brimmer and Ekiwah Adler-Beléndez". Libre acceso, Susan Antebi y Beth E. Jörgensen (eds.), New York, Suny Press, 2016, pp. 63-77.

Kaminsky, Amy. Reading the Body Politic: Feminist Criticism and Latin American Women Writers. Minneapolis, University of Minnesota Press, 1993.

Kafer, Alison. Feminist, Queer, Crip. Bloomington, Indiana University Press, 2013.

Massumi, Brian. Parables for the Virtual. Movement, Affect, Sensation. Duke, Duke University Press, 2002.

McRuer, Robert. Crip Theory. Cultural Signs of Queerness and Disability. New York, NY University Press, 2006.

Mintz, Susannah B. Unruly Bodies. Life Writing by Women with Disabilities. Chapel Hill, The University of North Carolina Press, 2007. 
Mitchell, David y Snyder, Sharon. Narrative Prosthesis: Disability and de Dependence of Discourse. Michigan, The University of Michigan Press, 2000.

Mitchell, David y Snyder, Sharon. The Body and the Pysical Difference. Discourses of Disability. Ann Arbor, The University of Michigan Press, 1997.

Poniatowska, Elena. "La muerte de Gaby Brimmer", 1/04/2000. Disponible en: https://www.jornada.com.mx/2000/o1/o4/cul1.html

Rancière, Jacques. Política, policía, democracia. Santiago de Chile, LOM Ediciones, 2017.

Rancière, Jacques. El desacuerdo. Política y filosofía. Buenos Aires, Nueva Visión, 1999.

Rivera Garza, Cristina. Los muertos indóciles. Necroescrituras y desapropiación. México, Tusquets, 2013.

Shakespeare, Tom. Disability. The basics. New York, Routledge, 2018.

Siebers, Tobin. Disability Aesthetics. Ann Arbor, The University of Michigan Press, 2010.

Siebers, Tobin. "A Sexual Culture for Disabled People". Sex and Disability, Robert McRuer y Anna Mollow (eds.), Durham/Londres, Duke University Press, 2012, pp. 37-53.

Siebers, Tobin. Disability Theory. Ann Arbor, The University of Michigan Press, 2008.

Taylor, Sunaura. Beasts of Burden. Animal and Disability Liberation. New York, The New Press, 2017. 
Villaplana Ruiz, Virginia. "Agencia”. Barbarismos queer y otras esdrújulas, Lucas R. Platero, María Rosón y Esther Ortega (eds.), Barcelona, Edicions Bellaterra, 2017. 